\title{
Historia y crítica del arte Intento de desnaturalizar sus conversiones recientes
}

\author{
Art History and Criticism \\ An Attemp to Alter Its Recent Changes
}

\author{
Ana Lía Gabrieloni \\ ana.gabrieloni@conicet.gov.ar \\ Laboratorio Texto, imagen y sociedad \\ (LabTIS). \\ Universidad Nacional de Río Negro \\ Sede Andina. \\ CONICET. Argentina
}

Recibido: 9/10/2017

Aceptado: 21/1/2018

\begin{abstract}
Resumen
La historia del arte, escribió André Malraux (1951), es la historia de todo lo que puede ser fotografiado. A mediados del siglo pasado, el uso expandido de la fotografía y del cine en la historia y en la crítica del arte invita a rever cómo los discursos de estas disciplinas fueron adaptándose y, sobre todo, explotando las posibilidades expresivas de soportes eminentemente (audio) visuales en detrimento del medio escrito tradicional al que habían permanecido asociados, en gran medida, desde su origen en los escritos de Plinio el Viejo, Giorgio Vasari y Denis Diderot.
\end{abstract}

\section{Palabras clave}

Imagen; historiografía; crítica del arte; musée imaginaire

\begin{abstract}
The history of art is the history of that which can be photographed, André Malraux (1951) wrote. There has been a widespread use of photography and film as media for art history and criticism since the mid-twentieth century. It invites us to consider how their discursive forms have been adapting to and, above all, drawn on the expressive potential of essentially (audio) visual medium. And how this has happened to the expense of traditional written form to which art history and criticism have been mainly associated since their origin in the works by Pliny the Elder, Giorgio Vasari and Denis Diderot.
\end{abstract}

\section{Keywords}

Image; art historiography; criticism; musée imaginaire 
I.

En el siglo XIX, el diálogo precoz que entablaron la literatura de viajes y la fotografía puso a esta última al servicio de las políticas expansionistas de países como Francia: es sabido que el colonialismo y la fotografía aportaron al imaginario positivista dominante en la época dos de las evidencias del anhelado progreso. Como consecuencia de lo anterior, entre 1850 y 1860 , se observa que "[...] la fotografía se impone como forma de reproducción y reemplaza al dibujo» (Brossard-Gabastou, 2013, p. 52; Lacoste, 2013) en los ensayos arqueológicos resultantes de expediciones francesas a Egipto y a regiones de Oriente. Tal es el caso del tratado Jerusalém: étude et reproduction photographique des monuments de la Ville Sainte (1856), del pintor devenido en reconocido fotógrafo, Auguste Salzmann (1824-1872), quien llegó a compartir viajes con el artista Eugène Fromentin, así como con el arqueólogo y político Félicien de Saulcy.

Herederas del enciclopedismo del siglo XVIII, las imágenes que Salzmann registra en Palestina aspiran a revestirse con un valor documental por sobre el meramente ilustrativo o estético (Foliard, 2016). Con todo, una de esas fotografías sorprende dado que se adelanta a las composiciones experimentales de las vanguardias artísticas [Figura 1]. La misma exhibe sobre una superficie lisa un par de fragmentos correspondientes a esculturas antiguas, una hebrea y otra romana. Por un lado, la imagen retiene esa dualidad primordial de la idea de Europa que, según George Steiner (2006), permite ser sintetizada en una historia en dos ciudades (Roma y la misma Jerusalén) y, por el otro, emana de ella el ritmo intermitente entre lo ausente y lo presente que -en línea con la reflexión teleológica de Salvatore Settis (2004) sobre las ruinas- demarca la memoria de tal historia.

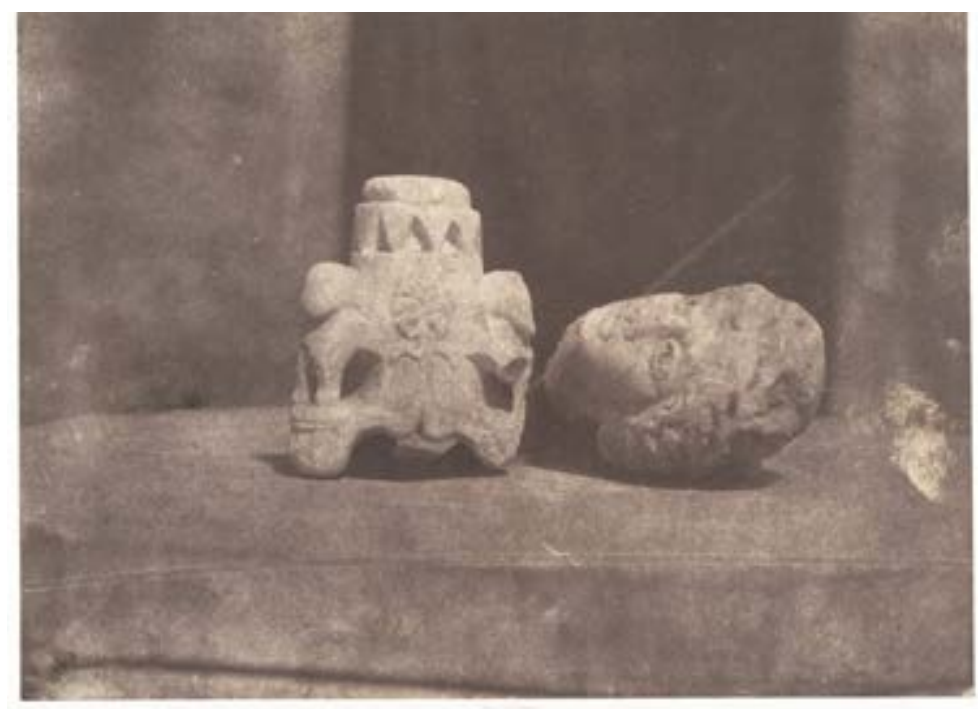

Figura 1. Jérusalem, fragments judaïque et romain (1854), Auguste Salzmann. Calotipo en impresión fotográfica de Louis Désiré Banquart-Évrard. 23,5 X $30,9 \mathrm{~cm}$ (Colección Gilman, 2005) 
A la derecha de la fotografía yace una cabeza cuyos ojos espabilados se fijan en el vacío con intención tan inquebrantable como aquella que los talló en la piedra. A la izquierda se mantiene en pie un fragmento que se revela irreconocible, más allá de la organización simétrica de sus formas curvas en cuatro partes con un remate en el extremo superior. El registro de Salzmann sugiere una analogía con una conocida fotografía de Man Ray, de 1926, que lleva por título Noire et blanche [Figura 2]. Esta última imagen también se desprende de la intersección entre dos mundos. La mano de una joven blanca sostiene una máscara africana sobre la mesa donde ella ha dejado caer su propia cabeza con los ojos cerrados. El cierre de esos párpados sella el destino de ese rostro: ser objeto de la apropiación de la mirada de los otros, así como la máscara y la cultura que ésta refiere fueron objeto de la apropiación colonialista. Casi un siglo separa a ambas fotografías, que dan a leer una historia, inscripta sin sangre, donde la sangre corrió en abundancia, en medio de guerras de religión, la expansión imperialista, la diáspora y la Shoá, la lucha de clases y la resistencia feminista.

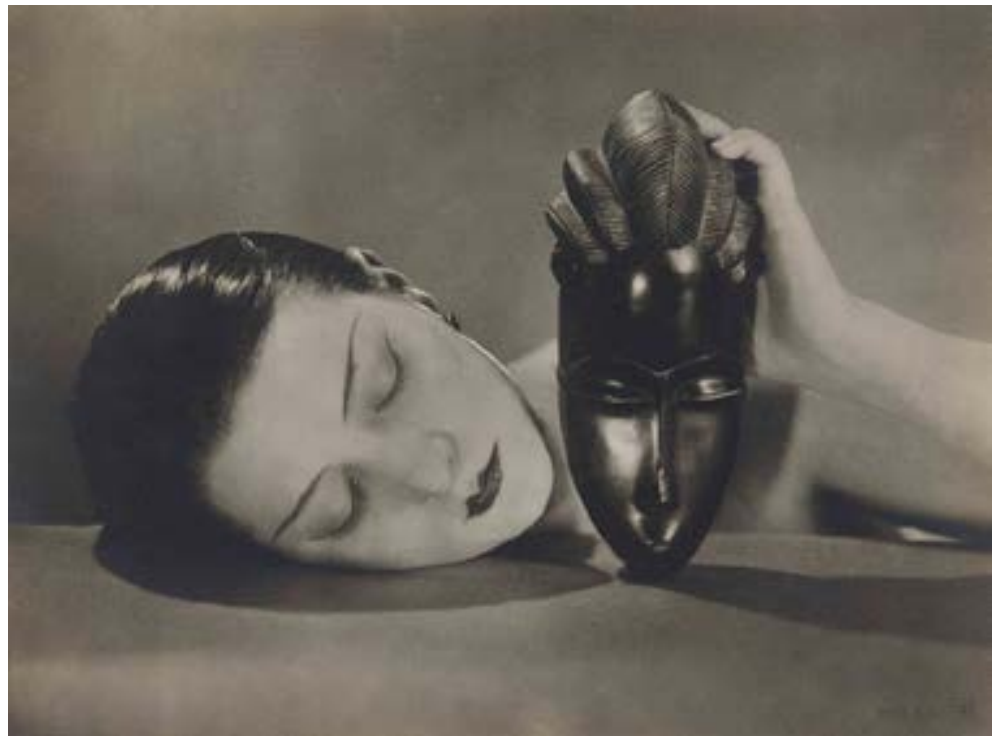

Figura 2. Noire et Blanche (1962), Man Ray. Impresión en plata sobre gelatina de Man Ray. 17,5 x $21 \mathrm{~cm}$

Entre las dos fotografías, la voluntad comparatista parece no obrar más allá de la visible discordancia sobre la cual se funda una especie de acuerdo formalista que nos estimula a apreciar el valor estético de estas imágenes. Sin embargo, en el caso de Salzmann, pionero en el uso de la fotografía asociada a la arqueología, tal apreciación se extiende y compromete, en paralelo al plano estético, el plano documental.

En este punto, vale considerar la introducción en el libro sobre Jerusalén, donde el fotógrafo viajero afirma haber reunido unas ciento cincuenta placas fotográficas de todos los monumentos 
vistos en el lugar. Declara que, frente a tan sorprendentes hallazgos, buscó vanamente en cuál página de la historia del arte abrir un paréntesis donde poder ubicar semejante repertorio de obras olvidadas (Salzmann, 1856). Dicha página no existía, ya que nunca nadie la había reclamado. No existía, además, porque se trataba de una página con la novedad de incluir fotografías, es decir, lo que Salzmann define como hechos de acabada contundencia.

A la luz de estas últimas consideraciones, el espacio interpuesto entre los dos fragmentos adquiere un carácter performativo dado que, mientras expone la distinción de las respectivas pertenencias a dos culturas monumentales, otorga un sustrato artístico a la fotografía donde se refleja un ápice de éstas. Una suerte de conciencia de la distancia vuelca la escultura de estilo romano hacia el pasado encerrado en la ruina enigmática. Mas dicho rostro no observa ese pasado con el horror que Walter Benjamin ([1973] 1989) lee en El ángel de Paul Klee, al cual dedica la écfrasis, quizá, con mayor espesor de sentido en la historia dada su ontología filosófica. Aquí - donde la técnica de la fotografía se halla sustraída del inmemorial tiempo histórico- solo cabe la apatía, no hay lugar entre las dos piezas para el ejercicio o para el rechazo de las influencias.

En la fotografía de Man Ray, el gesto alusivo de la mano sobre la máscara remite a un texto que, a su vez, alude al arte no europeo del artista August Macke y es publicado en el Almanaque de Der Blaue Reiter en 1912 con el título "Die Masken». En relación con los recaudos afines a la pureza del linaje artístico de una cultura, allí se advierte que los estilos pueden llegar a extinguirse por incesto (Kandisnky \& Marc, [1965] 2010). Sin duda que no es de esto último, sino de la prolífica tensión que anida entre el rostro de la joven y la pieza africana, que la composición de Man Ray deviene un incontestable manifiesto. Suma expresión de la revuelta en contra de la estética tradicional, esta fotografía (como la de Salzmann) participa del curso del arte conceptual — del cual es una manifestación temprana-, así como del curso de conceptualización de la cultura —-donde interviene de forma radical-en ese momento de apogeo de las tecnologías visuales y audiovisuales, hacia la primera mitad del siglo pasado.

Dicho apogeo coincidió, por un lado, con el uso expandido de la imagen fotográfica en los textos de historia del arte que comenzaron entonces a reclamar una mirada doble: como libros-objetos visuales a la par que como fuentes de conocimiento (Dufrêne, 2002); y, por otro lado, con el cine, donde la temporalidad propia del medio aloja la intemporalidad hacia la que se predisponen las imágenes como documentos, que dan forma hacia los años cincuenta a esa memoria de la memoria que es el ensayo documental (Gabrieloni, 2014) y su variante exclusivamente referencial al arte, tal como la exploraron Hans Cürlis, en Alemania; Luciano Emmer, en Italia; Paul Haesaerts y Henri Storck, en Bélgica; y Alain Resnais, en Francia (Jacobs, 2011; Brunier, 2013). 
Hacia fines de los años cuarenta, Malraux concebía el musée imaginaire que contaría para su difusión con el respaldo de la editorial suiza Skira. Algunos especialistas observan que las inéditas relaciones dadas entre los textos y las imágenes reunidos en la colección de Malraux escapan a satisfacer las exigencias metodológicas de la historia del arte (Dufrêne, 2002). En efecto, para Ernst Hans Gombrich (1954), tales rapsodias sobre arte son convincentes: su autor parece no haber permanecido jamás un día entero trabajando en el interior de una biblioteca. En cambio, según apunta Gaëtan Picon (1959), uno de los más diestros intérpretes del pensamiento del autor de La Condition Humaine (1933), éste avizoró cómo superar mediante la escritura el conflicto entre la integridad espiritual y la eficacia práctica sustituyendo la acción con la creación. Dicho de otra forma, sin llegar a ser Spinoza pero tampoco Lenin, restituyéndole valor a aspectos de la historia del arte que habían permanecido relegados en la historiografía tradicional, André Malraux (1951) expone en su musée imaginaire al mundo en metamorfosis dado que, materia absoluta de la creación, lo que se hace visible en las imágenes del arte no es otra cosa más que dicho mundo. Y dicha visibilidad nos recuerda que la historia del arte -en cuanto escapa a los especialistas- es la historia de lo que puede ser fotografiado (Malraux, 1951).

La publicación del Musée imaginaire (1947) deviene en tributo a la vez que es prueba irrefutable de esta última afirmación: consiste en tres volúmenes con galerías de imágenes silentes, combinadas cada dos páginas que empujan a un punto extremo - según precisa el mismo autor- la «inacabada confrontación» entre las obras exhibidas en los museos reales (Malraux, 1951, p. 14). Esta técnica es reminiscente de la que Salzmann y Man Ray aplicaron al componer las fotografías que comentamos al inicio. Ahora bien, la evidencia de tan palpables correspondencias no debería abismar en el olvido los genuinos antecedentes del museo imaginario de Malraux, que pueden recuperarse distinguiendo dos genealogías: una literaria y otra iconográfica.

II.

La primera de dichas genealogías remite a la tradición grecolatina tanto a través de la retórica ciceroniana como de las prácticas regidas por los progymnasmata, dado que se manifiesta tempranamente en la serie de descripciones de objetos artísticos en los dos libros de Eikones, de Filostrato el Viejo (ss. II-III d. C.), en la parte conservada de las Eikones de Filostrato el Joven (s. III d. C.), y en las Ekphraseis de Calistrato (s. III d. C.) sobre estatuas. La literatura francesa del siglo XVII enaltece por su parte la práctica descriptiva de cuadros provistos por la imaginación o conservados en la memoria en el Cabinet de Monsieur de Scudéry (1646), donde se lee una colección de poemas inspirados en más de un centenar de obras transpuestas en versos como pinturas parlantes. Injusto sería excluir de esta genealogía los cuadros verbales concebidos a modo de directivas para allanar el camino de un arte que, no 
antes de mediados del siglo XIX, llegó a rehuir de la tiranía de la figuración narrativa. Entre ellos se destacan dos ejemplos, que mencionaré sin mayores comentarios. En el libro Tableaux tirés de l'lliade, de l'Odyssée, et de l'Enéide (1742), el Conde de Caylus selecciona y glosa en clave descriptiva escenas extraídas de los tres grandes poemas épicos, proporcionando a los pintores de su época una galería verbal que asegura, en el ámbito de la pintura, representaciones ajustadas a los términos de las fuentes literarias, ineludibles en el marco de la tradición clasicista. Algunos años más tarde, Jean-Jacques Rousseau reescribe escenas completas de Julie ou la Nouvelle Heloïse (1761) para un único lector, el grabador Hubert-François Gravelot, a cargo de realizar las estampas ilustrativas que se publicarían intercaladas en la misma novela. Lo que persiste en el orden de la descripción en estos dos últimos ejemplos articula cuadros verbales semejantes a vaticinios respecto de las representaciones visuales que de ellos debían desprenderse en manos de los artistas (Gabrieloni, 2008).

En la genealogía literaria del museo imaginario se inscribe, asimismo, Die Gemälde (1798), de August Schlegel, consistente en un diálogo donde tres visitantes en la Galería de Dresde recrean -adoptando diferentes puntos de vista - mucho más que las obras allí exhibidas. Las impresiones que éstas suscitan, a la par que la conciencia sobre la singularidad de tales impresiones, aportaron a la radical reformulación de la estética clásica debida al Romanticismo, cuyo programa interartístico se expresa largamente en la galería descriptiva elaborada por uno de los personajes, Louise. Más recientemente, la habilidad de los maestros flamencos para reproducir abigarradas colecciones de arte en el interior de una pintura y la ambigüedad que la técnica del trompe l'oeil imprime en la mímesis -en tanto reafirma a la vez que interroga la fiabilidad de la percepción visual frente a representaciones hiperrealistasinspiran al escritor Georges Perec para la trama de la novela Un Cabinet d'amateur (1979). La misma se constituye a través de la mise en abîme de imaginería pictórica en el cuadro homónimo de la novela, realizado a principios del siglo pasado por un tal Henrich Kürz. Catálogo comentado de una colección de pinturas multiplicada ad infinitum, el relato de Perec rehúye la repetición mecánica de la mera copia a la vez que resulta una apología de esta última.

De esta breve novela, así como del diálogo de Schlegel, se desprenden intangibles galerías de imágenes a la par que una crítica de los presupuestos elementales de la creación estética. Con los términos del mismo Malraux, es posible sostener que si el museo es equivalente a una afirmación, el Musée imaginaire plantea un interrogante. Este último escritor no fue ciertamente el primero en concebir una historia del arte prescindente de las palabras y a base únicamente de imágenes; contaba, sin embargo, con escasos antecedentes en esa genealogía visual del museo imaginario que distinguimos a la par que la literaria recién comentada: el Museo cartaceo, de Cassiano dal Pozzo, de principios del siglo XVII, incluye una colección de estampas que reproducen obras de la tradición 
1 A principios de los años noventa, el Warburg Institute comenzó a reunir y a difundir los contenidos originarios del Museo de Papel de Cassiano dal Pozzo en casi cuarenta volúmenes distribuidos en tres series temáticas. En cuanto a la obra de Warburg, existe una edición en castellano que comprende las alrededor de 200 imágenes dispuestas sobre los paneles que debieron ser reconstruidos para su reproducción en el libro: Atlas Mnemosyne (2010), de Aby Warburg.
2 Jacobs (2011) destaca que Malraux concibe el libro de arte como una película, donde las sucesivas imágenes obedecen a la lógica del montaje. clásica, y el Atlas Mnemosyne, concebido por Aby Warburg a principios del siglo pasado, alberga una constelación de imágenes provenientes de todos los períodos y ámbitos de la cultura, dispuestas sobre paneles de tela, que resultan en una heterogénea galería móvil. ${ }^{1}$

¿En qué medida estos proyectos pudieron haber prefigurado esa inversión a la que quedó sometido el logocentrismo del apotegma de la crítica de arte del romanticismo alemán solo se puede hablar de la poesía con poesía, cuando Francis Ponge (1977) imagina el catálogo ideal de una exposición compuesto por reproducciones en miniatura de las obras artísticas sin dejar espacio a las palabras, al texto, y da a ver imágenes con imágenes? Acaso Malraux halló en la articulación de las reproducciones fotográficas - a costa de la supresión del relato escrito en los textos de historia— el lenguaje más acabado sobre el devenir de las imágenes en una época cuyo arte se caracteriza por no contar: la aparición del arte moderno tiene lugar sobre el final del «arte de la ficción» (Malraux, 1951, p. 98).

III.

Interesa ahora comenzar a percibir las dimensiones de un fenómeno que halló en ese final su inicio ante todo y que depositó un interés exclusivo en las imágenes para hablar de las imágenes. Ya mencionamos a los primeros realizadores en documentar obras de arte en lenguaje cinematográfico hacia la mitad del siglo pasado, cuando Malraux era retratado en su estudio frente a las láminas en blanco y negro que estaban destinadas a componer su museo imaginario. Lo anterior sugiere que lo propio de la época fue un contexto de múltiples interferencias entre la imaginería artística, las renovadas posibilidades técnicas de su reproducción en los libros sobre arte, y los ensayos filmográficos (en el doble sentido del término ensayo, como experimento y como género). $Y$ dicho contexto sugiere, en consecuencia, asociaciones entre las reproducciones contiguas a doble página del Musée imaginaire de Malraux con el montaje en el cine. De allí que George DidiHuberman (2013) no dude en alinear la estrategia fotográfica de Malraux con la escuela de Serguéi Eisenstein, y en concluir que dicha estrategia se edifica sobre la base de la pulsión inasimilable de las diferencias. Esta es una cabal y adecuada apreciación sobre las fotografías de Salzmann y de Man Ray que suscitaron las primeras reflexiones aquí anotadas. ${ }^{2}$

Las referidas transposiciones críticas de las imágenes del arte en el cine documental remiten al ensayo filmográfico, así como este remite a la deuda que historiadores del arte como Kenneth Clark mantuvieron con la prosa de arte de estilo impresionista debida a autores ingleses del siglo XIX: William Hazlitt, Charles Lamb y Algernon Swinburne. La mención de Clark adquiere relevancia en el contexto de las inéditas intersecciones aquí observadas entre las imágenes, el ensayo como crítica de arte y el cine documental a mediados del siglo pasado, porque fue el guionista y director de 
una exitosa serie en trece capítulos (producida y filmada en $35 \mathrm{~mm}$ y color por la BBC 2) titulada Civilisation, «el equivalente televisivo de un historiador del arte que dicta una serie de conferencias ilustradas con diapositivas" (Walker, 1993, p. 78). Desde la primera emisión -afirma John Walker en su estudio seminal de los documentales sobre arte en la televisión de Gran Bretañase advierte «el poder de un medio audiovisual como la televisión para animar la estática imagen artística» (Walker, 1993, p. 79). En el primer capítulo, el montaje interviene para presentar iconografía de la civilización grecorromana en contraste con la de los pueblos nórdicos bárbaros; así, la cabeza del Apolo de Belvedere alterna con el detalle del mascarón de proa de un navío vikingo. El recurso visual es reminiscente de la fricción entre las figuras retratadas en las fotografías de Salzmann y de Man Ray pero, en el caso de la serie televisada, no se desaprovechan las bondades del sonido para crear un efecto de suspenso que transforma el acecho en estocada final. Roma cae y, con ella, la civilización cristiana y occidental que se corresponde - para Clark - con el Occidente sobre el que Oswald Spengler había escrito los dos volúmenes de Der Untergang des Abendlandes (1918).

La perspectiva del escritor, crítico y artista John Berger en la serie Ways of Seeing - televisada también en la BBC 2, a través de cuatro episodios de treinta minutos cada uno, en 1972- contrapesa el eurocentrismo de su exitosa predecesora. Concebida a partir del texto de Benjamin «Das Kunstwerk im Zeitalter seiner technischen Reproduzierbarkeit» (1936) y difundida ampliamente en ámbitos universitarios - gracias, precisamente, a la posibilidad de su reproducción en copias de $16 \mathrm{~mm}$ antes de la aparición del video-, Ways of Seeing fue la primera realización televisiva en implementar un análisis sociológico-marxista del arte europeo, atento al revisionismo de las representaciones de las mujeres promovido por las feministas de entre los años sesenta y setenta, así como a la necesidad de analizar la iconografía publicitaria de la sociedad de consumo contemporánea. Aún más, dio como resultado un libro titulado igual que la serie, objeto permanente de reimpresiones en varios idiomas (la edición más reciente en castellano es de 2016). Algunos capítulos de este libro consisten exclusivamente en imágenes, por lo que no dudamos en inscribirlos en la genealogía de los museos imaginarios iconográficos comentada en el primer apartado de este trabajo. Dichos pictorial essays son deudores de Warburg, tal como observa Walker (1993), así como también —es preciso decirlo- de Malraux.

Las secuencias iconográficas hasta aquí seleccionadas y comentadas son reveladoras sobre cómo los avances tecnológicos promovieron una reinvención discursiva de la historia y de la crítica de arte durante el último siglo y medio, en tanto - desde la temprana predilección de la fotografía hacia las obras de arte hasta el inédito tratamiento de estas últimas en formatos cinematográficos y televisivos - se advierte cómo se fue extendiendo la práctica de hablar sobre imágenes con imágenes y en ellas. Esa especie de 
3 Observamos un ejemplo de tales migraciones en el trabajo "L'Objet d'art filmique. Le critique comme artiste» (presentado en el Congreso La Critique à l'écran, Université de Pau et des Pays de l'Adour, (Francia, 2015): el film Civilización (Guzmán, 2012) sobre la obra de León Ferrari (1920-2013). Dejando a un lado la catalogación enumerativa y descriptiva de la iconografía de Ferrari para incurrir en el terreno ensayístico, el documental museo-marco crítico de esas imágenes-es una obra de arte en sí mismo y posee un trabajo exquisito de montaje audiovisual. impulso endógeno de los museos imaginarios contemporáneos de Malraux, Emmer, Clark, Resnais y Berger intervino la tradicional forma escrita de la historia y de la crítica del arte y favoreció su expansión en soportes analógicos, desde donde los textos y las imágenes - allí depositados a mediados del siglo pasado-fueron migrando en simultáneo hacia el video y hacia los medios digitales más actuales. ${ }^{3}$ Lo anterior invita a revisar la historiografía de la historia y la crítica de arte recientes atendiendo a las modalidades expresivas propias de los formatos audiovisuales que han ido adoptando. Solo así será factible apreciar los inestimables aportes que ciertos films de autor sobre artistas y sus obras (films d'art) suman en relación con el estado actual de las configuraciones del universo del arte en el plano histórico y en el plano crítico.

\section{Referencias}

Benjamin, W. (1989). Tesis de filosofía de la historia. En Discursos interrumpidos I (pp. 175-192). Madrid, España: Taurus.

Brossard-Gabastou, L. (2013). Auguste Salzmann (1824-1872). Pionnier de la photographie et de l'archéologie au Proche-Orient. Paris, Francia: Harmattan.

Brunier, E. (2013). De l'écran au tableau, I. Images Re-vues, (11). Recuperado de http://imagesrevues.revues.org/3178

Didi-Huberman, G. (2013). L'Album d'art à l'époque du «Musée imaginaire». Paris, Francia: Hazan \& Musée du Louvre.

Dufrêne, B. (2002). L'édition d'art des années 1950-1970: des promesses non tenues. Communication et langages, (134), 22-38. Recuperado de http://www.persee.fr/web/revues/home/prescript/article/ colan_0336-1500_2002_num_134_1_3169

Foliard, D. (2016). Orientalismes? Études photographiques, (34). Recuperado de http://journals.openedition.org/ etudesphotographiques/3605

Gabrieloni, A. L. (2008). Écfrasis. Eadem utraque Europa, (6), 83-108.

Gabrieloni, A. L. (2014). El ensayo documental: la poética del disentimiento. En A. Gerbaudo (ed.), IX Congreso Argentino de Literatura (pp. 42-49). Recuperado de http:// www.fhuc.unl.edu.ar/centros/ cedintel/argentino.pdf

Gombrich, E. H. (1954). André Malraux and the Crisis of Expressionism. The Burlington Magazine, 96(621), 374-378.

Jacobs, S. (2011). Framing Pictures. Film and the Visual Arts. Edimburgo, Escocia: Edinburgh University Press.

Kandinsky, Vasili y Franz, Marc (2010). El jinete azul. Der Blaue Reiter. Madrid. Paidós

Lacoste, A. (2013). Édition photographique et sciences de l'Antiquité. Revue de la $B N F, 44(2)$, 18-24. Recuperado de https://www.cairn.info/ revue-de-la-bibliotheque-nationale-de-france-2013-2-page-18.htm

Malraux, A. (1951). Les Voix du silence. París, Francia: Gallimard. 
Picon, G. (1959). Malraux par lui même. París, Francia: Seuil.

Ponge, F. (1977). Atelier contemporain. París, Francia: Gallimard.

Salzmann, A. (1856). Jérusalem: étude et reproduction photographique des monuments de la Ville sainte. París, Francia: Gide et J. Baudry.

Settis, S. (2004). El futuro de lo clásico. Madrid, España: Adaba.

Steiner, G. (2006). La idea de Europa. Madrid, España: Siruela.

Walker, J. (1993). Arts TV: History of British Arts Television. Luton, Reino Unido: University of Luton Press. 